\title{
Same-same but different: Integrating central university support and faculty-specific knowledge for mentor training. A Practice Report
}

Deborah Rodrigo, Cassie Khamis, Peter Lead, Zinnia Sahukar, Nadia McDonagh, and Melanie Nguyen

University of Sydney, Sydney, Australia

\begin{abstract}
Mentoring literature often cites a tension between local initiatives that target the needs of specific groups and more efficient centralised programs addressing common concerns across a larger population. For several years, the University of Sydney has had a Mentoring Network consisting of the faculties of Arts and Social Sciences, Health Sciences, Science, Sydney Law School and the Business School. These faculties have worked together to develop a community of best practice for mentoring programs at our large, multi-campus institution, and for the past two years have included a representative from Student Support Services to incorporate a centralised support component into their faculty-specific training programs. This Practice Report showcases the work of the University of Sydney Mentoring Network in combining central university services with faculty-based mentoring.
\end{abstract}

Please cite this practice report as:

Rodrigo, D., Khamis, C., Lead, P., Sahukar, Z., McDonagh, N., \& Nguyen, M. (2014). Same-same but different: Integrating central university support and faculty-specific knowledge for mentor training. A Practice Report. The International Journal of the First Year in Higher Education, 5(2), 111-117. doi: 10.5204/intjfyhe.v5i2.236

This practice report has been accepted for publication in Int J FYHE. Please see the Editorial Policies under the 'About' section of the Journal website for further information.

(C) Copyright of practice reports is retained by authors. As an open access journal, articles are free to use, with proper attribution, in educational and other non-commercial settings. ISSN: 1838-2959 


\section{Introduction}

Peer-mentoring programs have demonstrated success in supporting the first year student experience (Heirdsfield, Walker, Walsh, \& Wilss, 2008). Research has shown that mentoring enables an institution to provide support for first year by fostering a sense of belonging, promoting a quality first year experience and promoting access to life and learning support (Mekdessi, Curan, Lam, Grech, \& Nguyen, 2013).

The benefits of mentoring are enhanced when mentors are provided with formal training in their role. Comparing the experiences of mentors who had and had not been trained, Bryant and Terborg (2008) found that trained mentors engaged in more knowledge creation and sharing and had a stronger mentoring community. The training evaluated by Bryant and Terborg provided mentors with general skills in mentoring (e.g. what is a mentor, managing communication, providing feedback).

A limitation of general training programs, as with generalist mentoring programs, is a reduced ability to provide students with tailored experiences (Hudson, 2004). For higher education, this is particularly important as first years are introduced to not only a different style of learning but to an institution and learning community. Study expectations, attendance requirements and platforms for developing friendships - all crucial to a successful first year - vary from faculty to faculty (Scutter, Palmer, Palmer, Luzeckyj, Burke da Silva, \& Brinkworth, 2011). Therefore, mentors need training in not only how to be mentors but also how to support students in a specific university and faculty context.
This paper describes three successful approaches to integrating centralised student support training and facultyspecific training for mentoring programs at the University of Sydney. These approaches reflect the diversity of student needs across different faculties. The aims of each approach were to provide:

1. Consistent messages about mentors roles and responsibilities, in particular around duty of care.

2. Standardised training from a qualified counsellor for appropriate referral to student support, and dealing with students in distress.

3. Accurate information and contact details for Student Support Services.

4. Faculty-specific information such as key contacts, the structure of the program, common degree-specific concerns of first year students. And

5. A sense of community and belonging amongst mentors.

The centralised component was run in two parts: (1) a counsellor from Counselling \& Psychological Services (CAPS) conducted a session on the roles and responsibilities of a mentor, how to appropriately refer their mentees to support, and dealing with a distressed mentee, while (2) a Student Transition and Retention Team (STAR) representative presented on Student Support Services and conducted a short role-play activity. This training component was created in a way that could be adapted to suit the needs of each faculty-specific program, and focuses on enhancing the discipline knowledge by concentrating on the support services most relevant to the faculty group. 
Three approaches to integrated mentor training

\section{Once-off face-to-face training; Focus on mental well-being}

In addition to the transition aspect of student mentoring programs generally, the Law program has the aim of fostering positive mental health and creating openings for discussions about mental health issues. The mentoring program aims to raise awareness of mental health risks, reduce competition among the cohort and provide a social support network.

Law students (and lawyers generally) have been identified as having a higher risk of experiencing high levels of distress, anxiety and depression than other groups (Kelk, Luscombe, Medlow, \& Hickie, 2009). The introduction to the mentoring program at the Law School Orientation sessions mentions some of these statistics: that one in three Law students in the study reported high or very high levels of anxiety or distress; and that the people they are most likely to turn to for support are family and friends. The mentoring program is introduced as a way to develop social bonds with their peers, and who can engage in discussion about topics which might be the source of anxiety or distress: exams, high expectations of their performance, perfectionism, high workloads, the competitive nature of studying law.

The role of the mentor is to facilitate the creation of these social networks, and to be a guide through the early stages of studying law. Mentors and other mentees provide a point of contact for students who might be experiencing distress or anxiety and can assist them in seeking assistance from the University's counselling service.
Mentor training has a larger contribution from central student support than other programs to allow more time to explore the role of student services. Mentors have more time to become comfortable with the process of referring a student to the counselling service, and to ensure that they, the mentors, are prepared for discussions about distress, anxiety or isolation. The student support section is approximately half of the training provided to mentors, based on feedback from mentors that they already have the necessary skills to lead a mentor group. The remaining training time is devoted to mentors sharing their experiences so they have a range of information to draw on to assist their mentee group.

\section{Combined online and face-to-face training}

Challenges for mentors in these faculties include supporting students studying large classes (e.g. 2000+ students in first year biology), students who study at a satellite campus (Faculty of Health Sciences' clinical degrees) or students studying across two campuses where the sense of belonging and sense of community is diluted. Mentors are required to be familiar with university services (sometimes across different campuses), support first years through the expectations and processes of university and foster a degree- and faculty-specific identity and a sense of belonging to the university at large.

To support mentors, online and face-to-face training is provided during Summer break. Online training is delivered via activities on Survey Monkey (Science) or the university Learning Management System (LMS) (Health Sciences and Faculty of Health Sciences [FASS]). This training focuses on general mentoring skills (e.g. qualities of a 
good mentor, communication skills) and provides mentors with a schedule of events and notes on key people in learning and teaching (e.g. tutors, lecturers). Online training allows students to work through modules on their own while familiarising themselves with other mentors.

Face-To-Face training builds on the foundation concepts introduced in online training. Mentors receive a training manual to work through during the training. This manual also includes information on different services and discusses the roles of Student Services and CAPS to ensure mentors are able to identify and refer on students in distress and the services available to all students. Central university services also presents at the face-to-face training. This structure enabled students to develop an awareness of their role within the Faculty and university context.

\section{Ongoing mentor training}

The University of Sydney Business School and FASS train mentors through two faceto-face sessions separated by online activities. In order to capture the interest and commitment of mentors, they are required to attend a session before the end of the final semester in the year before mentoring. The online component keeps mentors involved in the program and varies between the two faculties to better cater for their students. The final session occurs just before orientation week, giving mentors the final information, and practical knowledge of the logistics of the program.

The first session includes information about the program, first year transition and involves practical examples of peer-to-peer mentoring scenarios with icebreaker activities, planning activities utilising the Internet and phone apps. Mentors learn the skills needed to lead a group through role- play based activities and discussion. These are presented by CAPS and Student Services.

Online activities vary between the Faculties. Business mentors participate in an online forum by responding to a particular question. This gives mentors a chance to contribute to the collective knowledge of the mentoring team as responses are used to develop sample mentor agendas for mentoring sessions. In FASS, mentors complete two online quizzes as an interactive way of learning about the university and common problems faced by first year students. Both online programs build on the foundation of active learning as an effective approach to facilitating learning and increasing student engagement with content (Kaufman, 2004).

Held much closer to the start of their mentoring role, the second training session is aimed at empowering mentors to own the process of mentoring. For Business students, using the questions and answers posted over the break, information and sample agendas are created for mentors to use in their meetings with first year students. In the Faculty of Arts and Social Sciences, mentors engage in small group activities and planning the first year survival tour. Mentors also begin to plan for activities during Weeks 1-3. Mentors receive $t$-shirts and a second session with CAPS and Student Services (FASS) is provided to outline and refresh mentors' knowledge of the university services available to them and their mentees.

\section{Mentor development}

A large part of building the sense of belonging is made through the investment into mentor development. Due to the different needs and career outcomes of students, ongoing mentor development is

114 | The International J ournal of the First Year in Higher Education, 5(2) August 2014 
offered in slightly different forms between the Business School, the Faculty of Health Sciences and the Faculty of Arts and Social Sciences.

Business School mentors are provided with a proforma to record their mentoring experiences (for their own use only) throughout the program. Mentors are then invited to participate in a mentor resume and interview professional development session. The Business School Careers and Employability Office provides a session on translating experiences into practical examples.

Mentors are invited to register on a volunteers list. Many of the Business School volunteer events and opportunities to do public speaking arise from being on the Peer mentoring volunteers list. Mentors who register for the list, and have a proven record with the Mentor program, are invited to use the Program Coordinator as a referee when applying for employment or other business school initiatives (e.g. industry placement programs). As student leaders, all the mentors are invited to the Business School end of year Student Leadership conference. This is an exclusive event provided in recognition of students of the Business School who show leadership qualities throughout the year.

In line with the Faculty commitment to community building and fostering student leadership, Health Sciences mentors are invited to participate in the Faculty of Health Sciences Alumni Mentoring program. Students are assigned a mentor to support their transition to the health workforce. This one-on-one relationship is designed to help students set goals for their future, think more creatively about health careers and discuss ways of communicating their current experiences for employment.
Health Sciences mentors are invited to a Mentors and Alumni Evening where, students are provided with an opportunity to learn from a panel of alumni and engage in informal networking with key people in the health sector. Mentors are also thanked with a certificate presentation ceremony. Feedback from this evening is overwhelmingly positive with students sending in unsolicited comments about the value of meeting and speaking with alumni.

In Arts and Social Sciences, mentors who are keen to expand their involvement are invited to join the Mentor Taskforce; a dedicated group of student volunteers who share their skills and experiences at first year enrolment, event preparation and support. In both of the Faculties of Arts and Social Sciences and Science, mentors are invited to a tailored session in collaboration with the University's Careers Centre. The session focuses on developing their resume, networking skills, and employability by harnessing their volunteer experience.

\section{Evidence of the effectiveness of training}

Positive feedback has been received from mentors as a result of an integrated approach to training. In Health Sciences, students reported greater engagement with the training due to the diversity of speaker. When asked to comment on aspects of the training that they liked, common comments were:

The CAPS presentation was very interesting and useful, as well as the info on the services available.

Students reported the relevance and helpfulness of both faculty-delivered $(\mathrm{M}=$ 8.38/10, 8.03 respectively) and centrally- 
delivered $(\mathrm{M}=8.95,8.78$ respectively) sessions as high ${ }^{1}$.

Some responses from Business School students when asked what some of the successes of the mentor training included

The talk by Patrick was very informative and gave me insight into the counselling services available as well as how to approach someone who may want to use those services...

\section{And}

I could classify (sic) the boundaries to help them.

\section{Outcomes of the discussion at the $17^{\text {th }}$ International First Year in Higher Education Conference in Darwin Australia, J uly 2014.}

For a number of institutions, the issue of ownership was important, particularly where programs had sprung up either in a silo or spontaneously in a manner that suggests they were addressing an immediate need. Given that these programs are important not only to students, but also to stakeholders, making sense of them and exploring collaborative possibilities is challenging. For those who were working in this type of environment, the possibility of reviewing the support and engagement services for commencing students was suggested as a viable starting point.

In other institutions, there was already a network of mentoring and a first year transition program managers' network in place. There was discussion about areas of overlap, economies of scale and collaborative work to create shared resources.

Participants from a number of institutions discussed the possibility of centralised training for core mentoring program components followed by face-to-face training for program specific training. At one institution, general leadership and mentoring skills and information is presented in a suite of online modules. Students complete these and are issued a printable certificate that they take to their specialised mentor training. Discussion around this model included the benefits of having a common baseline for all mentors participating in a particular institution's set of programs. This created the situation where mentors were able to participate in numerous targeted sessions for different programs without duplicating training material for mentors participating in a variety of roles across an institution. Also, dedicated time is available for programspecific material and practical exercises in mentoring in the particular programs context by having students complete online modules for general information and instruction,

For both areas, where there were institution-wide and Faculty-based or student group based programs, there was discussion about creating collaborative partnerships as a way to create a platform for innovation across the program, not only mentor training. This was suggested not only within institutions where staff could participate in the process, but also by drawing on the extensive first year student support peer mentor program networks across Australian and New Zealand

1 The two means are for the perceived relevance and perceived helpfulness. They were asked as two different questions because we felt that they were two distinct constructs. The four numbers are for relevance and helpfulness of either the faculty or centrally delivered training. The " $/ 10$ " is to provide readers with some context - that the scores were out of 10 (Authors)

116 | The International J ournal of the First Year in Higher Education, 5(2) August 2014 
universities. In response to this, attendees were invited to join an online group to share ideas, discuss problems and issues and to collaborate where appropriate. If you are interested in joining the online group or would like further information, contact:

\section{Nadia McDonagh}

(nadia.mcdonagh@sydney.edu.au) or

Deborah Rodrigo

(deborah.rodrigo@sydney.edu.au)

\section{References}

Bryant, S., \& Terborg, J. (2008). Impact of peer mentor training on creating and sharing organizational knowledge, Journal of Managerial Issues, 20,1129.

Heirdsfield, A., Walker, S., Walsh, K., \& Wilss, L. (2008). Peer mentoring for first-year teacher education students: the mentors' experience. Mentoring and Tutoring: Partnership in Learning, 16(2), 109-124. doi: 10.1080/13611260801916135

Hudson, P. (2004). Specific mentoring: A theory and model for developing primary science teaching practices. European Journal of Teacher Education, 27, 139-146. doi: $10.1080 / 0261976042000223015$

Kaufman, D. (2004) Applying education theory in practice. In D. Cantillon, L. Hutchinson, \& D. Wood (Eds.), $A B C$ of learning and teaching in medicine (pp. 1-4). London: BMJ Books.

Kelk, N., Luscombe, G., Medlow, S. \& Hickie, I. (2009). Courting the blues: Attitudes towards depression in Australian law students and legal practitioners BMRI Monograph 2009-11, Sydney, Australia: Brain \& Mind Research Institute.

Mekdessi, R., Curan, B., Lam, B., Grech, A. \& Nguyen, M. (2013, July). Health Sciences peer-mentoring: A student-staff-alumni collaboration. Paper presented at the $16^{\text {th }}$ International First Year in Higher Education Conference. Retrieved from http://fyhe.com.au/past papers/papers13/4C. pdf.

Scutter, S., Palmer, E. Luzeckyj, A., Burke da Silva, K. \& Brinkworth, R. (2011). What do commencing undergraduate students expect from first year university? The International Journal of the First Year in Higher Education, 2(1), 8-20. doi:10.5204/intjfyhe.v2i1.54 